\title{
Impacts of COVID 19 Total Confinement on Rural Youth Food Security
}

\author{
Abdoulaye Fofana Fall ${ }^{1,2,}$, , Joseph Ssekandi ${ }^{1}$, Amos Kipkemoi Ronoh ${ }^{1}$, Samuel Obeng Apori ${ }^{1}$, \\ Abibatou Ndiaye ${ }^{2}$, Beatrice Wamuyu Mbugua ${ }^{1}$ \\ ${ }^{1}$ African Center of Excellence in Agroecology and Livelihood Systems, Faculty of Agriculture, Uganda Martyrs University, Nkozi, Uganda \\ ${ }^{2}$ Fungi Biotechnology Laboratory (LBC), Department of Plant Biology, Cheikh Anta Diop University of Dakar (UCAD), Dakar, Senegal
}

Email address:

abdallahfall@outlook.fr (A. F. Fall)

${ }^{*}$ Corresponding author

\section{To cite this article:}

Abdoulaye Fofana Fall, Joseph Ssekandi, Amos Kipkemoi Ronoh, Samuel Obeng Apori, Abibatou Ndiaye, Beatrice Wamuyu Mbugua. Impacts of COVID 19 Total Confinement on Rural Youth Food Security. Journal of Food and Nutrition Sciences.

Vol. 9, No. 4, 2021, pp. 99-105. doi: 10.11648/j.jfns.20210904.11

Received: May 24, 2021; Accepted: June 10, 2021; Published: July 13, 2021

\begin{abstract}
Uganda is amongst the countries in Africa which have experienced total confinement during the COVID 19 outbreak. The impacts of the COVID 19 pandemic will have disproportionate effects on populations with higher existing vulnerability. Youth consistently experience higher levels of food insecurity than adults and are more likely to be dependent upon informal employment. The present study aimed to understand the impact of COVID 19 total confinement on youth food security in the rural Mpigi District of Uganda. The study targeted rural youths and questions were asked as to whether the COVID 19 pandemic led to food insecurity. Using self-administered questionnaires, data were collected from 380 respondents selected randomly from Nkozi sub-county. Both descriptive and inferential statistics were used to analyze collected data. Nested binary logistic regressions was used to examine the relationship between food security-sex-education levels. The study established that $75 \%$ of youth were classified as food insecure. Female youths were more likely to be food secure than males. The study also revealed that a high level of education significantly contributes to youth food security. This study reinforces the importance of including social determinants of food security, such as sex and level of education in the policies targeting youth food security. Giving food relief, reduce food taxes and allowing the business to open are three of the major recommendations from this study.
\end{abstract}

Keywords: COVID 19, Food Security, Youth, Total Confinement

\section{Introduction}

The outbreak of coronavirus is not only a public health emergency causing large-scale loss of life but also posing a major threat to global food security, especially in Subsaharan Africa. The pandemic is having widespread effects on food security, nutrition, and the overall functioning of food systems [1-3]. The spread of the pandemic is disrupting food systems and undermining food and nutrition security of households $[4,5]$.

Hunger is often linked to a problem of accessibility, availability, stability and utilization [6]. Hunger is associated with the sharp rise in food prices associated with economic constraints, conflicts leading to political instability and unusual climatic conditions [7]. COVID 19 pandemic is already significantly affecting economic activity at global, regional and local levels. According to World Bank [8], the pandemic is likely to push 88 to 115 million people into extreme poverty in 2020, a third of these being from sub-Saharan Africa while the World Food Programme [9] and the Food and Agriculture Organization [10] project that the pandemic will almost double the number of people facing acute food insecurity from 135 million to 265 million, by the end of 2020 .

The government-imposed confinement and mobility measures $[8,11]$, which have disrupted livelihood activities, thereby reducing individual incomes [12]. These confinements 
and restrictions are also disrupting food supply chains and community services which result in higher food prices $[13,14$, 9]. The impact of COVID 19 is also expected to vary across livelihood options, with those activities that require face-toface interactions likely to experience a significant loss in demand [15]. Closure of informal food markets, where the poor obtain the majority of their food, maybe more deadly in terms of food security impacts than the virus itself. In 2018, the U.S. Government's global hunger and food security initiative, known as Feed the Future found that over 30\% of the population in Uganda faces some level of chronic food insecurity and malnutrition [16]. This trend could rise with the impacts that COVID 19 will have on the food security level in Uganda, both for supply and demand. COVID 19 impacts will be mediated by existing socio-economic variation within populations including poverty, inequality, price or demand increases, food shortages and interrupted supply routes. Populations already experiencing high food insecurity, particularly, the youths have been identified as among the most vulnerable to the economic activity impacts of COVID 19.

In Uganda, the confinement remained in force for about 10 weeks. These measures restricted the movement of residents and led to the closure of business operations, and the ban of transport linking confinement areas with the rest of the country. However, to cushion the citizens against the adverse economic effects of the pandemic, the government of Uganda announced various policy guidelines and financial stimulus packages. An analysis of the impacts of COVID 19 on rural youth economic activities and food security will help bring further to light the nature and extent of these effects. Also, the projections of future impacts on food security and planning for pathways to adaptation are predicated on an understanding of how current food systems are affected by COVID 19. This understanding includes a comprehension of the causal mechanisms by which the impacts of COVID 19 manifest through - and are mediated by - social determinants of activities. We contribute to this research gap by assessing the impacts of COVID 19 total confinement on youth food security. The objective of this study was to explore the degree to which total confinement of COVID 19 is associated with food security status among youth in a rural area of Uganda. Understanding the level of impacts of the COVID 19 pandemic on youth's food security and economic activities is critical for designing effective policies and interventions to mitigate the adverse effects of the pandemic.

\section{Methods}

\subsection{Area of Study}

This research was situated in Nkozi-subcounty in the district of Mpigi in central Uganda. This location is approximately 8 kilometers, north of Lake Victoria. The district headquarters is $37 \mathrm{~km}$ South West of Kampala the capital. The number of households in the sub-county 10,279 [17]. It is located between latitudes $00,00,36 \mathrm{~N}$ and longitude 32, 00, 00 E. Livelihood change and coping farming is the main activity in this area. Other economic activities include petty trade, Charcoal burning, sand mining, brick making, services and artisans. The selection of Nkozi Sub-county was informed by a study carried out in Nkozi under World Vision Uganda that showed $38 \%$ of the youth were food insecure. This food insecurity prevalence is high compare to the national rate, hence requiring urgent attention.

\subsection{Sampling Methods}

The study useed Krecjcie and Morgan (1970) table to determine the sample size. The total population of Nkozi Sub-county is 48,000 people in 2020 , with $77 \%$ of youth [18]. This represents 37,114 youths in the sub-county [18]. When using Krecjcie and Morgan (1970) table, the sample size is approximately 380 respondents at $95 \%$ confident interval. A simple random sampling technique was used to select respondents. We started from a central location of the Sub-county, spun a pen to identify a random direction then followed the direction to get eligible youths. The study units of the baseline survey included youths in the age range 15-35 years, 380 respondents were randomly selected. The data were collected from April to June 2020. The inclusion criteria for youths in the study were being residents, having stayed in the study area for not less than 6 months. The exclusion criterion was the refusal to participate and any show of unwillingness to participate.

\subsection{Data Collection}

We carried out a cross-sectional survey in Nkozi from April to June 2020. Each youth was asked to complete the survey questionnaire in self-completion format. The questionnaire included the socio-economic status of youth and 10 questions (table 1) out of the 18 HFSS (household food security survey) items with the wording described by [19] but with appropriate adjustment for self-administration. The HFSS can be applied successfully in different developing and developed country contexts. This is based on four underlying domains of food insecurity (access): (1) anxiety and uncertainty about household food supply, (2) insufficient food quality, (3) insufficient food intake, and (4) its physical consequences. According to established procedures from the US Department of Agriculture, households are classified as food insecure if they endorse $\geq 3$ affirmative responses to 10 total questions [19]. Respondents were required to complete every item with no items skipped or screened out. The instruments were first pre-tested over a week in Nkozi with 30 respondents. Issues addressed included ambiguous questions and English words that were confusing to the respondents. Besides, some questions that would elicit more useful information for the study were added. To counter the potential biases in the study, we discussed preliminary findings with the team. The validity of findings was assured by identifying representative and appropriate quotations for the issues under discussion, and crosschecking with members of the research team and literature. 
Table 1. Adapted Household Food Security Survey (HFSS).

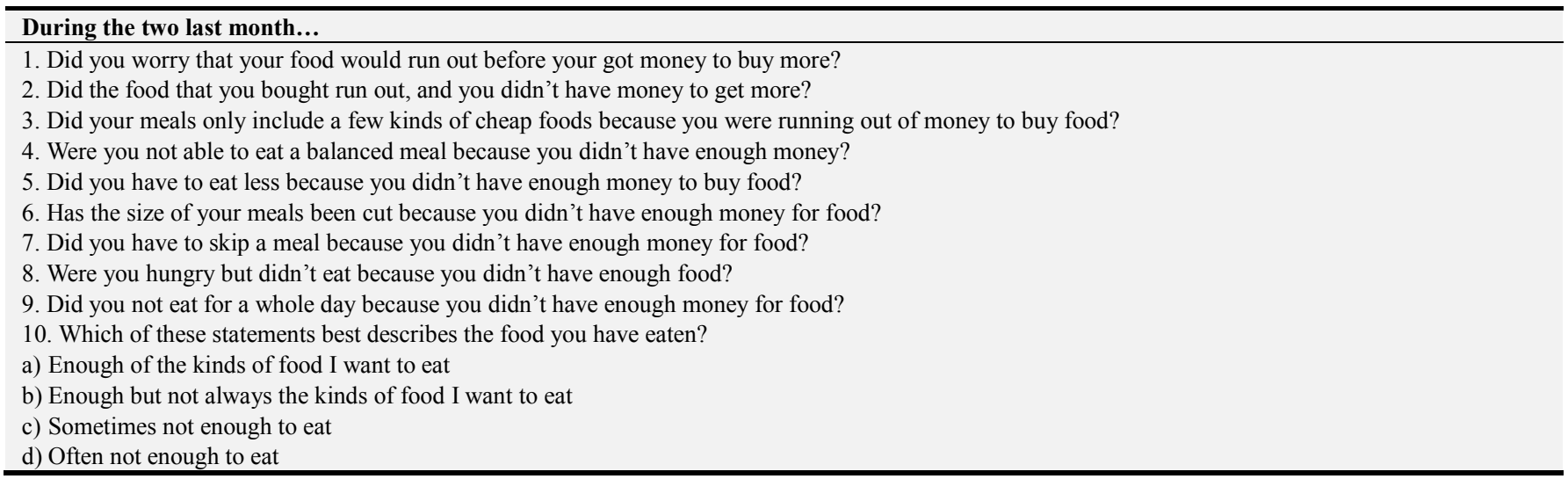

\subsection{Data Management and Analysis}

The data collected to measure the food security of youth were entered into SPSS software (version 20) then statistically analyzed. The data have been assumed to be complete for all youth and the number of affirmative responses has been calculated. We categorized youth based on their responses to the HFSS question items. We coded affirmative responses to the initial questions as 1 and negative responses as 0 . We then summed up the item responses to calculate the raw food security scale score ranging between 0 and 9 points, with 0 correspondings to the most food-secure youth and 9 to the most food insecure. We then generated a three-tier food security categorization based on guidelines by reference to a table of the standard values estimated for the U.S. population from the Current Population Survey (CPS) food security data. For policy and research purposes, food security status was simplified into 3 categories (Food secure, Food insecure without hunger and Food insecure with hunger), each one representing a meaningful range of severity on the underlying status. Food security status was then coded using recommended cut-points for youth (food secure, zero to two affirmatives; food insecure without hunger three to five affirmatives; food insecure with hunger, six to ten affirmatives. All data were analyzed using both descriptive analysis and inferential analysis. Logistic regression was used to conclude the relationships between food security and sex, educational level and youth economic activities. The following independent variables were included in the model: sex, education level and economic activities. We then computed logistic regression to establish the relationship between food security and sex, education level and economic activities. We combined the two categories of food insecure youth (food insecure without hunger and food insecure with hunger) to form a binary dependent variable (food secure and food insecure house youths).

\section{Results}

\subsection{Basic Characteristics of the Study Participants}

Table 2 shows the basic characteristics of the study participants. The study sample included 198 males (52.1\%) and 182 females $(47.9 \%)$, with mean age of $24.4 \pm 4.7$ years. The youth were $42.1 \%$ married and $57.8 \%$ single. For education, $100 \%$ of the respondents had attained some level of education (Table 1). Of these, 49\% attained secondary education and $51 \%$ had advanced to post-secondary school level education (i.e., university, tertiary, institute etc.).

\subsection{Impact of Total Confinement on Youth Economic Activities}

The impact of COVID 19 total confinement on youth activities is shown in Table 2. A few respondents of $35 \%$ of youth worked less hours, $27 \%$ stopped working, $21 \%$ had no customers, $15 \%$ did not receive payment and $2 \%$ lost their job.

\subsection{Youth Food Security Status}

Youth food security was measured with HFSS. The status of food security during the lockdown period is presented in Table 3. The status of hunger during the total confinement was distributed as follows: $25 \%$ of youth were food secure, $29 \%$ of youth were food insecure without hunger and $46 \%$ of youth were food insecurity with hunger.

\subsection{Relationship Between Food Security and Sex-Level of Education-Youth Economic Activities}

We generated a binary logit model (Table 4). In the analysis, food security (1) is the reference category and was compared with the category of food insecurity (0). The resulting model significantly fit the data as exhibited by the omnibus tests of significance. The model demonstrates that sex and educational level both significantly distinguishes food secure and food insecure youth $(p<0.05)$. However economic activities do not significantly distinguish food secure and food insecure youth $(\mathrm{p}>0.05)$. Male respondents were less likely to be food secure than female respondents. In another word, the probability of being food secure increases when the youth is female. The probability of being food secure falls with a low level of education. In other word, the youth that has low level of education are more likely to become food insecure. 


\subsection{Coping Strategies to Ovoid Food Insecurity}

Some of the youths in the present study had to cope with food insecurity by resorting to offering labor in exchange for food (44\%), borrowing food (7\%), rationing of food $(9 \%)$, eating from relatives and friends $(6 \%)$ and using savings (34\%) (Table 5).

Table 2. Basic characteristic of study participants.

\begin{tabular}{|c|c|c|}
\hline \multicolumn{3}{|l|}{ Age } \\
\hline Mean & Median & Mode \\
\hline $24.4 \pm 4.7$ & 25.0 & 20.0 \\
\hline Gender & Frequency & Percent \\
\hline Male & 198 & 52.1 \\
\hline Female & 182 & 47.9 \\
\hline \multicolumn{3}{|l|}{ Marital status } \\
\hline Married & 160 & 42.1 \\
\hline Single & 220 & 57.8 \\
\hline \multicolumn{3}{|l|}{ Level of Education } \\
\hline Secondary & 186 & 48.9 \\
\hline University & 103 & 27.1 \\
\hline Tertiary & 91 & 23.9 \\
\hline \multicolumn{3}{|l|}{ Type of livelihood } \\
\hline Formal employment & 87 & 22.8 \\
\hline Small business & 160 & 42.1 \\
\hline Commercial farming & 23 & 6.0 \\
\hline Wage earning & 38 & 10.0 \\
\hline Informal employment & 72 & 18.9 \\
\hline \multicolumn{3}{|c|}{ Effect of total confinement on youths economic activities } \\
\hline Stop working & 103 & 27.1 \\
\hline Work less hours & 133 & 35.0 \\
\hline No customers & 80 & 21.0 \\
\hline Payment stopped & 57 & 15.0 \\
\hline Lost job & 7 & 1.8 \\
\hline
\end{tabular}

Table 3. Food security status of youth in Nkozi.

\begin{tabular}{lll}
\hline Youth food security status & & \\
\hline Number of affirmative responses out of $\mathbf{1 0}$ & Number of youth & Food security status \\
\hline 0,1 , and 2 & 95 & Food secure \\
3,4 , and 5 & 110 & Food insecure without hunger \\
$6,7,8,9$ and 10 & 175 & Food insecure with hunger \\
\hline
\end{tabular}

Table 4. Binary logistic regression of food security with sex, educational level and economic activities in Nkozi.

\begin{tabular}{|c|c|c|}
\hline Independent variables & Model & \\
\hline & Coef. & Odds ratio \\
\hline Sex the youth (reference category $[\mathrm{RC}]=$ female) & $1.69 *$ & 5.45 \\
\hline Economic activities $(\mathrm{RC}=$ farming $)$ & 0.30 & 1.34 \\
\hline $\mathrm{R}^{2}$ & 0.181 & \\
\hline$\chi^{2}$ & 19.91 & \\
\hline
\end{tabular}

The dependent variable is food security status $(0=$ food insecure; $1=$ food secure $)$

*Significant at $\mathrm{p}=0.05$.

Table 5. Strategies to cope with food insecurity.

\begin{tabular}{llll}
\hline Strategies & Number of Responses (100) & Number of youth & Percent (\%) \\
\hline Offering labor & 380 & 43.9 & 167 \\
Borrowing food & 380 & 26 & 7.5 \\
Rationing food & 380 & 36 & 9.5 \\
Eating from relatives and friends & 380 & 22 & 129 \\
Using savings & 380 & 5.7 & 39.9 \\
\hline
\end{tabular}




\section{Discussion}

\subsection{Proportion of Nkozi Youth Food Secure}

In this study, we aimed to estimate the categories and cutoffs of the food security status for youth in the period of COVID 19 total confinement. The results presented in the previous sections suggest several potential explanations for the observed impacts of total confinement on the food security of youth. Overall $75 \%$ of the youth across Nkozi were food insecure. This is very high compare to the food security level among the youths in this area before COVID 19 outbreak. Indeed, according to [20] and [21] more than $24 \%$ of the youth in Uganda are unable to meet their minimum dietary energy requirements over one year in the period from 2016 to 2018 . Moreover, in $2015,38 \%$ of youths in Nkozi were food insecure [22]. This insecure food status can be because the total confinement corresponds also to the hungry-gap rainy season defined as May to July, which is at the beginning of the rainy season and before the first harvest. During this time, food availability is low and agricultural physical activity levels are high, poor market access because the movement was banned and food supply interfered with. Most farmers had not to harvest food yet. Another major limiting factor for youth in this area is low food availability due to poor crop harvests and low food stocks at household level due to the effects of prolonged dry spells and crop and livestock diseases [22, 23].

\subsection{Relationship Between Sex-Levels of Education - Food Security Statuses}

Education level is not always sufficient for the realization of food security outcomes but it is an important complement to social capital as a determinant of positive food security outcomes. Our results showed that youths with high education level were more likely to be food secure, with the odds increasing by $85 \%$ (model). This result confirms [24] revealing that a high level of education of the household head improves food security status. The probable explanation is linked to the likelihood of youth with the better-educated level being able to access a good job and consistent income necessary for buying food, better than the less educated members. One possible explanation is that youths with high education level tend to be more entrepreneur and through enterprise, they access more resources that contribute to food security and also, education opens avenues for alternative employment and hence additional income to access food. Education empowers youths through access to knowledge and information on recommended food security and nutrition practices. The literature on sex points to inequities, with females being disadvantaged compared to males in this regard $[25,26]$. Our results in contrary showed that female were more food secure than male in Nkozi in the context of COVID 19 total confinement. The odds of being food secure were 5.45 if a youth were female (model). The observed prevalence of food security was in line with the prevalence of the national prevalence in rural areas in Uganda [27, 28, 29, 30]. Similar results have been obtained in Midwest USA where being male is a significant determinant of decreased food security [31]. In these studies results showed that women were more food secure than men. This is not surprising given the evidence from East Africa where it is shown that women's income has greater positive effect on food security than men's income $[32,28]$. A probable explanation of this finding is women in Uganda play significant roles in maintaining food production, food availability and nutrition security because they are more involved in farming activities, keeping kitchen-gardens, generally responsible for food preparation and lastly, societal and cultural norms assign them the role of ensuring that household members receive an adequate share of available food. Another probable explanation for this phenomenon is that in some African cultures women are often perceived as vulnerable, therefore men can deprive food themselves to give it to them [33].

\subsection{Study Limitations}

The intention of this study was to obtain more information regarding the food security status of youths during the period of COVID 19 total confinement in a rural area in Uganda. Although the study provided data regarding these youths, there were also limitations. One limitation was that this study was conducted in a single district because transport was banned. While these results reflect the needs of these youths, they may not reflect other youths in other rural areas, making it difficult to generalize the results. A second limitation is that, although the participants answered anonymously, they may have given inaccurate answers for fear of the researchers revealing their real identities.

\section{Conclusion and Recommendations}

This study offers new information regarding total confinement which can be an obstacle to the food security of youths. Total confinement limits youth's ability to secure food. In Uganda, the age range between 15 and 35 is the most economically productive and tends to be the breadwinner and total confinement negatively influences those age range activities which also negatively influences food security. This study confirms that being female and having a high level of education positively impact the food security of youths. Despite minor limitations, the creation of this survey instrument and the information that was obtained are invaluable in better understanding the food needs of youths in a rural population. Surveys such as the one used in this present study could be conducted in another area to examine the food needs of their youth populations. By identifying youths who are facing a food insecurity problem, local authorities can intervene, potentially increasing the resilience of this vulnerable population. Thus, we recommend the government to unlock the country, release transport and allow the business to open although this should be 
accompanied by some sanitary measures like putting on masks, washing hands or sanitizing before to enter in shops. We propose the government to give loan to youth to start up self-employment. We also suggest the government to give food relief, reduce taxes and food prices.

\section{Ethical Approval and Participants Consent}

The researchers got approval from the participants for their consent. The objective of the survey and the nature of the data to be collected was well explained to them. All aspects contained in the consent form, including voluntary participation, the right to refuse to answer a question and the right of withdrawal, as well as the fact that there will be no material or monetary compensation have also been well explained to participants. Participants, on condition of anonymity, reflected and gave verbal consent to the interviewers.

\section{Availability of Data and Materials}

The authors want to declare that they can submit the data at any time based on the publisher's request. The datasets used and/or analyzed during the current study will be available from the authors on reasonable request.

\section{Competing Interests}

The authors declared no potential conflicts of interest concerning the research, authorship, and/or publication of this article.

\section{Funding}

The Regional Academic Exchange for Enhanced Skills in Fragile Ecosystems Management in Africa (REFORM) program provided financial support to complete this research succesfully.

\section{Authors' Contributions}

AFF contributed to the inception of the paper, field methods, analysis and writing. JS contributed to the inception, field methods and reviews of the paper. AN contributed to inception, field methods and reviews. SOA contributed to data management, analysis and review of the drafted manuscript. BWM contributed on inception and reviewed the work. RAK contributed to write up.

\section{Acknowledgements}

The authors are grateful to Prof. Juluis Mwine and Mr. Comfort Turyatemba who were very helpful in giving advices. The authors thank all the participants in this research.

\section{References}

[1] McDonald, A. J. (2020). Key indicators for monitoring food system disruptions caused by the COVID-19 pandemic: Insights from Bangladesh towards effective response. Food security, 12 (4), 761-768. https://doi.org/10.1007/s12571-02001083-2

[2] Barrett, D. (2020). Dreams about COVID-19 versus normative dreams: Trends by gender. Dreaming, 30 (3), 216. https://doi.org/10.1037/drm0000149

[3] Devereux, S., Béné, C., \& Hoddinott, J. (2020). Conceptualising COVID-19's impacts on household food security. Food Security, 12 (4), 769-772. https://doi.org/10.1007/s12571-020-01085-0

[4] Swinnen, J., \& McDermott, J. (2020). COVID-19 and Global Food Security. EuroChoices. https://doi.org/10.1111/1746692X.12288

[5] Amjath-Babu, T. S., Krupnik, T. J., Thilsted, S. H., \& McDonald, A. J. (2020). Key indicators for monitoring food system disruptions caused by the COVID-19 pandemic: Insights from Bangladesh towards effective response. Food security, 12 (4), 761-768. https://doi.org/10.1007/s12571-02001083-2

[6] Béné, C. (2020). Resilience of local food systems and links to food security-A review of some important concepts in the context of COVID-19 and other shocks. Food Security, 1-18. https://doi.org/10.1007/s12571-020-01076-1

[7] Saaka, M. (2016). How is household food insecurity and maternal nutritional status associated in a resource-poor setting in Ghana?. Agriculture \& Food Security, 5 (1), 11. https://doi.org/10.1186/s40066-016-0059-3

[8] FAO, I. F. A. D., \& UNICEF. (2017). WFP and WHO (2018). The state of food security and nutrition in the world 2018 . Building climate resilience for food security and nutrition. http://www.fao.org/3/I9553EN/i9553en.pdf

[9] World Bank. 2020. Africa Pulse. Washington, DC: World Bank.

[10] World Food Program of the United Nations (WFP). 2020. 2020 Global Report on Food Crises. Retrieved from https://www.wfp.org/publications/2020-global-report-food-crises

[11] Food and Agriculture Organization of the United Nations (FAO). (2020). COVID-19: Our hungriest, most vulnerable communities face 'a crisis within a crisis.' Retrieved from http://www.fao.org/news/story/en/item/1269721/icode/

[12] Andam, K. S., Edeh, H., Oboh, V., Pauw, K., \& Thurlow, J. (2020). Estimating the economic costs of COVID-19 in Nigeria (Vol. 63). Intl Food Policy Res Inst.

[13] Arndt, C., Davies, R., Gabriel, S., Harris, L., Makrelov, K., Robinson, S.,... \& Anderson, L. (2020). COVID-19 lockdowns, income distribution, and food security: An analysis for South Africa. Global Food Security, 26, 100410. https://doi.org/10.1016/j.gfs.2020.100410

[14] Hirvonen, K., Mohammed, B., Minten, B., \& Tamru, S. (2020). Food marketing margins during the COVID-19 pandemic: Evidence from vegetables in Ethiopia (Vol. 150). Intl Food Policy Res Inst. 
[15] Mahajan, K., \& Tomar, S. (2020). COVID-19 and Supply Chain Disruption: Evidence from Food Markets in India. American journal of agricultural economics. https://doi.org/10.1111/ajae.12158

[16] Baldwin, R., \& Weder di Mauro, B. (2020). Economics in the Time of COVID-19.

[17] Feed the future. The U.S. Government's global hunger and food security initiative, 2018. https://www.usaid.gov/what-wedo/agriculture-and-food-security/increasing-foodsecurity-throughfeedfuture\#: : text=Feed $\% 20$ the $\% 20$ Future $\% 20$ is $\% 20$ America's,n eed $\% 20$ and $\% 20$ opportunity $\% 20$ for $\% 20$ improvement.

[18] UBOS, U. B. (2018). of S-, International ICF. Uganda Demographic and Health Survey 2011. 2012. Kampala, Uganda \& Calverton, Maryland, USA: UBOS \& ICF International Inc. https://www.ubos.org/wpcontent/uploads/publications/05_2019ST ATISTICAL_ABSTRACT_2018.pdf

[19] UBOS, I. (2020). International Inc. Uganda demographic and health survey, 315. https://dhsprogram.com/pubs/pdf/FR264/FR264.pdf

[20] Bickel, G., Nord, M., Price, C., Hamilton, W., \& Cook, J. (2000). Guide to measuring household food security. https://w ww.ers.usda.gov/briefing/foodsecurity

[21] USAID 2017. "Country Profile: Uganda." Available at: http://www.feedthefuture.gov/country/uganda

[22] Food and Agriculture Organization of the United Nations (FAO). (2019). The state of Food security and Nutrition in the World' Retrieved from. http://www.fao.org/3/ca5162en/ca5162en.pdf

[23] World vision Uganda (WVU). 2015. Child well-being reportWorld Vision international https://www.wvi.org/sites/default/files/Child\%20Wellbeing\%20report.pdf

[24] Apanovich, N., \& Mazur, R. E. (2018). Determinants of seasonal food security among smallholder farmers in southcentral Uganda. Agriculture \& Food Security, 7 (1), 1-10. https://doi.org/10.1186/s40066-018-0237-6

[25] Sseguya, H., Mazur, R. E., \& Flora, C. B. (2018). Social capital dimensions in household food security interventions: implications for rural Uganda. Agriculture and Human values, 35 (1), 117-129. https://doi.org/10.1007/s10460-017-9805-9

[26] Kabeer, N. (2005). Gender equality and women's empowerment: A critical analysis of the third millennium development goal 1. Gender \& Development, 13 (1), 13-24. https://doi.org/10.1080/13552070512331332273

[27] Atchoarena, D., \& Gasperini, L. (Eds.). (2005). Educación para el desarrollo rural. Bib. Orton IICA/CATIE. 10.22004/ag.econ. 165777

[28] Demographic and Health Survey (DHS), Uganda (2011).

[29] Silvestri, S., Sabine, D., Patti, K., Wiebke, F., Maren, R., Ianetta, M.,... \& Joash, M. (2015). Households and food security: lessons from food secure households in East Africa. Agriculture \& Food Security, 4 (1), 23. https://doi.org/10.1186/s40066-015-0042-4

[30] Schramm, S., Kaducu, F. O., Smedemark, S. A., Ovuga, E., \& Sodemann, M. (2016). Gender and age disparities in adult undernutrition in northern Uganda: high-risk groups not targeted by food aid programmes. Tropical Medicine \& International Health, 21 (6), 807-817. https://doi.org/10.1111/tmi.12708

[31] Mwavu, E. N., Kalema, V. K., Bateganya, F., Byakagaba, P., Waiswa, D., Enuru, T., \& Mbogga, M. S. (2018). Expansion of commercial sugarcane cultivation among smallholder farmers in Uganda: Implications for household food security. Land, 7 (2), 73. https://doi.org/10.3390/land7020073

[32] Dominick, S. R., Widmar, N. J. O., Ruple, A., Weir, J. Z. G., \& Acharya, L. (2018). The intersection of food insecure populations in the Midwest US and rates of chronic health conditions. Agriculture \& Food Security, 7 (1), 43. https://doi.org/10.1186/s40066-018-0195-Z

[33] Quisumbing, A. R., Brown, L. R., Feldstein, H. S., Haddad, L., \& Peña, C. (1996). Women: The key to food security. Food and Nutrition Bulletin, $17 \quad$ (1), 1-2. https://journals.sagepub.com/doi/pdf/10.1177/1564826596017 00116

[34] Shack, W. A. (1971). Hunger, anxiety, and ritual: Deprivation and spirit possession among the Gurage of Ethiopia. Man, 3043. DOI: $10.2307 / 2798425$. 